Cite As: Sheaves, M., Johnston, R., Johnson, A., Baker, R., \& Connolly, R. M. (2013). Nursery Function Drives Temporal Patterns in Fish Assemblage Structure in Four Tropical Estuaries. Estuaries and Coasts, 36:893-905.

\title{
Nursery function drives temporal patterns in fish assemblage structure in four tropical estuaries.
}

\author{
Marcus Sheaves ${ }^{1}$, Ross Johnston ${ }^{1 *}$, Ashlee Johnson ${ }^{1}$, Ronald Baker ${ }^{1,3}$, Rod M \\ Connolly ${ }^{2}$
}

${ }^{1}$ Centre for Tropical Water \& Aquatic Ecosystem Research, Estuary and Tidal Wetland Ecosystems, School of Marine and Tropical Biology, James Cook University, Townsville, Queensland 4811, Australia.

${ }^{2}$ Australian Rivers Institute - Coast and Estuaries, and School of Environment, Griffith University, Gold Coast, Queensland 4222, Australia.

${ }^{3}$ Current address: Centre for Tropical Water \& Aquatic Ecosystem Research, James Cook University, and CSIRO Land and Water, Australian Tropical Science and Innovation Precinct, James Cook University Townsville Campus, Townsville, Queensland 4811, Australia

*Corresponding Author

Email: ross.johnston@jcu.edu.au

Postal Address: TropWATER, Estuary and Tidal Wetland Ecosystems, School of Marine and Tropical Biology, James Cook University, Townsville Qld 4811, Australia Telephone: +61 (07) 47814626

Fax: +61 (07) 47251570 


\begin{abstract}
Despite estuary-to-estuary differences in assemblage composition, fish faunas of tropical Indo-Pacific estuaries show parallel patterns of temporal change suggesting a common set of ecological drivers. One potentially important driver is the interaction of different patterns of occupancy by functional groups that display different life-history patterns. However, most studies that have considered temporal change lack the detail needed to understand life-history utilisation. Most have focussed on changes in CPUE or probability of encounter, with only one study going further and investigating changes in size structure, and then only for a single estuary. One of the reasons for this lack of detail is the large volume of work needed to collect comprehensive data on size structures of species rich assemblages across multiple estuary systems over time. To overcome the logistical limitations on data collection, we used joint patterns of change in CPUE and mean biomass per fish (BPF) as proxies for changes in size structure. We investigated how different life-history strategies contributed to overall temporal patterns of assemblage change across 4 tropical Indo-Pacific estuaries. The 3 lifehistory strategies displayed characteristically different patterns in CPUE, BPF, and the relationships between CPUE and BPF that reflect differences in the way that the 3 groups use estuaries. These different patterns interacted to produce complex assemblage patterns that are likely to be sensitive to location-specific differences in the mix of species from each group, providing at least part of the explanation for the site specific fish assemblage structures that are characteristic of tropical estuarine fish fauna.
\end{abstract}

Key words: life-history; recruitment; nursery ground; estuary; fish; monitoring

\title{
Introduction
}

Estuarine fish assemblages around the globe are often numerically dominated by juveniles of species that spawn offshore (Blaber 1980, Deegan et al. 2000). However, offshore-spawned juveniles, or marine migrants, are just one of many life-history strategies found among estuarine fish faunas (Elliott et al. 2007). The various life-history strategies are defined by a range of patterns of occupancy and utilisation of estuarine systems. Processes driving changes in the abundance of species with different life-history strategies may occur at different times, and often in different ecosystems. Hence, identifying and managing impacts on estuarine systems and the fish that occupy them requires a clear understanding of the patterns and drivers of change in functional composition of fish assemblages.

The fish fauna of tropical estuaries in the Indo-west Pacific show consistent estuary-toestuary differences in assemblage composition (Ley 2005) reflecting differences in the contribution of species from a characteristic regional estuarine species pool (Sheaves and Johnston 2009). The differences between individual estuaries are substantial and more marked than differences among regions or climatic zones (Sheaves 2006; Sheaves and Johnston 2009). Despite these estuary-to-estuary spatial differences, assemblages show parallel patterns of temporal change in assemblage structure with, for example, predictable seasonal pulses of recruitment of offshore spawned juveniles (Sheaves et al. 2010). This 
suggests ecosystem functioning is broadly insensitive to the spatial variation in species composition. However, while the spatial and temporal patterns are reasonably well established, indicating consistency in ecosystem function and a common set of processes driving assemblage change, little is known about the nature of these drivers, either in a proximal or ultimate sense.

At the most proximal level, understanding the cause of pattern and change in fish assemblage structure requires detailed knowledge of patterns of change of the component fish species and life-history strategies. While this knowledge is progressing in some parts of the world (e.g. Aiken et al. 2005; Garcia et al. 2012), patterns of change in estuarine fish assemblages are poorly understood any many regions, especially in the tropics (Blaber 2002). In the only study of its kind in tropical Indo-Pacific estuaries, Robertson and Duke (1990a) showed substantial seasonal changes in the abundance and size structures of a number of species from one estuary in north-east tropical Australia that indicated a seasonal recruitmentmigration cycle of juveniles using the estuary as a nursery ground. The seasonal changes in the abundances of these offshore-spawned juveniles have been suggested as a major contributor to temporal change in assemblage structure in estuaries of the tropical IndoPacific (Sheaves et al. 2010) and elsewhere in the world (Deegan et al. 2000; Aiken et al. 2005; Barletta et al. 2005; Franco et al. 2008). However, estuary assemblages are comprised of a number of different life-history strategies (Elliot et al 2007), each with different patterns of occupancy, which combine to contribute to overall temporal patterns of assemblage change.

Several aspects of the few previous studies in tropical Indo-Pacific estuaries make the generality of the temporal patterns of occupancy of estuary fish difficult to assess. For instance, Robertson and Duke (1990a) only considered one estuary, Alligator Creek, combined data from a number of gear types, and had relatively small sample sizes for many species by time combinations. To understand the drivers of temporal patterns in estuarine fish assemblages comprising a number of life-history strategies, data on changes in size structure are needed in addition to the more regularly gathered data on abundance and species composition (e.g. Barletta et al. 2005). Subsequent studies in the tropical Indo-Pacific (Sheaves et al. 2010) have failed in this regard to extend the work of Robertson and Duke (1990a), primarily because the time involved in measuring all individuals from large samples of a large number of species from multiple estuaries makes obtaining more extensive data prohibitively expensive. Consequently there is a clear need to improve our understanding of temporal patterns of occupancy, and drivers of those patterns, in tropical estuaries to better inform management decisions.

The aim of the present study was to understand the drivers of temporal change in the estuarine fish assemblage, across four tropical estuaries. In particular, because the seasonal influx of offshore-spawned juveniles appears to be an important driver of temporal change in other regions (Deegan et al. 2000), we aimed to test the generality of Robertson and Duke's (1990a) findings, since it remains the only study of its kind in the tropical Indo-Pacific. To overcome the logistical limitations on data collection, we used joint patterns of change in catch per unit effort (CPUE) and mean biomass per fish (BPF) as proxies for changes in size 
structure. We investigated if groups with different life-history strategies displayed characteristically different patterns of temporal change in CPUE and BPF that reflected fundamental differences in the way they use estuaries, and if these differences in estuarine usage are likely to be important determinants of characteristic temporal changes in assemblage structure.

\section{Materials and methods}

Study Sites The study was conducted between November 2007 and January 2009 in four small (maximum $8 \mathrm{~km}$ navigable length) estuaries in tropical north Queensland, Australia (Cocoa, Crab, Doughboy and Hell Hole Creeks), spanning approximately $100 \mathrm{~km}$ of the drytropics coastline (Fig. 1). The estuaries were between 40 and $60 \mathrm{~m}$ wide at their mouths and narrowed to 5 to $15 \mathrm{~m}$ at the upstream limits of navigation. Maximum depths were approximately $3.5 \mathrm{~m}$ in downstream reaches at low tide and all became increasingly shallow with distance upstream, with only a few centimetres of water remaining at low tide upstream of the limits of navigation. All estuaries were mangrove lined for most of their lengths with extensive saltmarsh (dominated by Marine couch Sporobolus virginicus and/or succulents) and saltpan bordering the landward margins of mangrove forests and occurring on higher stream banks.

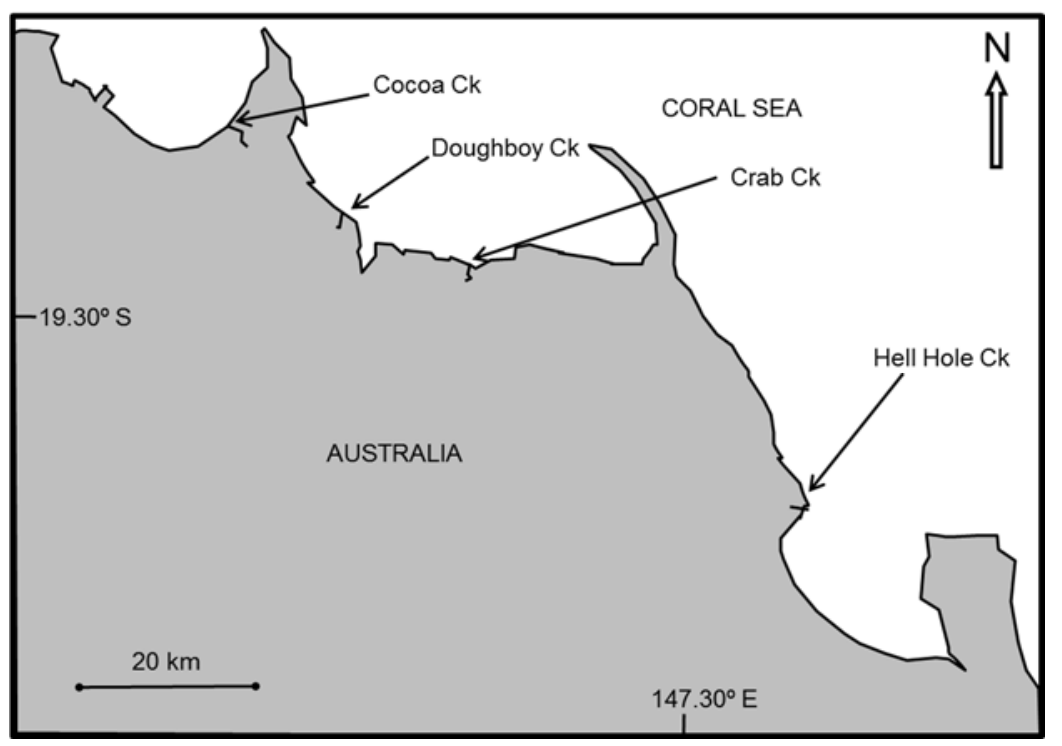

Fig. 1 Location map of the 4 study estuaries

The regional rainfall pattern features a distinct but variable hot wet season through January and February (but variably extending into late December or early March), and an extended dry period comprising; a post-wet season (March to May) when the weather cools but some rainfall may occur, a cool dry season (June to September) and a pre-wet season (October to December) when the weather begins to warm but little rain falls. The two wet seasons during the study were particularly intense, with $1047 \mathrm{~mm}$ of rainfall recorded between late January and February 2008, and 1615 mm during January and February 2009 at the Townsville weather station (BOM 2009). Tides in the region are semi-diurnal with a maximum range of about $4 \mathrm{~m}$. 
during January and February 2008 (Table 1). Preliminary evaluation of samples up to May 2008 indicated bi-monthly sampling would be sufficient to represent temporal change of the major species so sampling frequency was reduced to bi-monthly with the advantage of reductions in the number of fish that needed to be retained and processed; however additional samples were collected from Crab, Doughboy and Hell Hole Creeks in October and December 2008 to allow detection of the timing of the start of the summer recruitment season. No access was possible to Cocoa Creek at these times, again due to severe flooding (Table 1).

Table 1

Summary of sampling sites and times. Crosses indicate sampling occasions

\begin{tabular}{|c|c|c|c|c|c|c|c|c|c|c|c|}
\hline \multirow{2}{*}{$\begin{array}{l}\text { Season } \\
\text { Location }\end{array}$} & \multicolumn{2}{|c|}{ Pre-wet } & \multicolumn{3}{|c|}{ Post-wet } & \multicolumn{2}{|c|}{ Dry } & \multicolumn{3}{|c|}{ Pre-wet } & \multirow{2}{*}{ 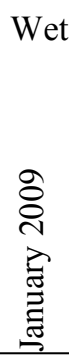 } \\
\hline & $\begin{array}{l}\hat{8} \\
8 \\
\text { - } \\
\dot{0} \\
\text { ह } \\
0 \\
0 \\
0 \\
z\end{array}$ & 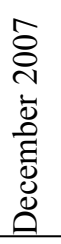 & 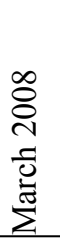 & 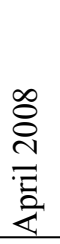 & 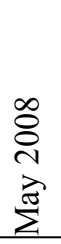 & 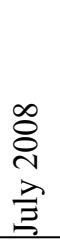 & 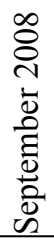 & 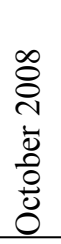 & 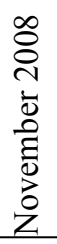 & 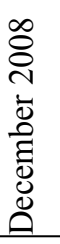 & \\
\hline Cocoa Creek & $X$ & $\mathrm{X}$ & $\mathrm{X}$ & $\mathrm{X}$ & $\mathrm{X}$ & $\mathrm{X}$ & $\mathrm{X}$ & & $\mathrm{X}$ & & $\mathrm{X}$ \\
\hline Crab Creek & $\mathrm{X}$ & $\mathrm{X}$ & $\mathrm{X}$ & $\mathrm{X}$ & $\mathrm{X}$ & $\mathrm{X}$ & $\mathrm{X}$ & $\mathrm{X}$ & $\mathrm{X}$ & $\mathrm{X}$ & $\mathrm{X}$ \\
\hline Doughboy Creek & $\mathrm{X}$ & $\mathrm{X}$ & $\mathrm{X}$ & $\mathrm{X}$ & $\mathrm{X}$ & $\mathrm{X}$ & $\mathrm{X}$ & $\mathrm{X}$ & $\mathrm{X}$ & $\mathrm{X}$ & $\mathrm{X}$ \\
\hline Hell Hole Creek & $X$ & $X$ & $X$ & $\mathrm{X}$ & $\mathrm{X}$ & $\mathrm{X}$ & $\mathrm{X}$ & $\mathrm{X}$ & $\mathrm{X}$ & $\mathrm{X}$ & $\mathrm{X}$ \\
\hline
\end{tabular}

Small estuaries were selected so that sampling could be conducted over the whole estuary system within one low tide cycle, with the aim of ensuring that species present would be consistently represented regardless of the extent to which they moved within the system. For this reason Alligator Creek, Robertson and Duke's (1990a) study site, was not included because it was too large to sample on a single tidal cycle. In each estuary, samples were collected haphazardly over the full extent navigable in the small boat used for sampling. 
Sampling sites were allocated to represent all habitat types available to the sampling gear, approximately in proportion to their linear extent. Sampling was also stratified within each estuary according to reach; upstream and downstream (and mid-estuary for the largest of systems), with sampling effort allocated equally among reaches. Initially 90 samples were collected from each of the estuaries but this was reduced to 45 on each subsequent occasion because preliminary analysis indicated that this provided equivalent representation of catch per unit effort (CPUE) and mean biomass per fish (BPF).

Sampling was conducted using small mesh monofilament drawstring cast nets $(2.4 \mathrm{~m}$ radius, $5 \mathrm{~mm}$ mesh), operated by the same individual throughout the study. Cast nets were used to facilitate rapid high levels of replication (Baker and Minello 2011) across the available range of unstructured habitats in each estuary (Johnston and Sheaves 2008). Tropical estuarine fish assemblages are dominated by small fish (Blaber 1980; Robertson and Duke 1990b) and cast nets provide a good representation (taxonomic composition, size structure) of small fish assemblages (Stevens et al. 2006, Baker and Minello 2011) however larger mobile species, and species associated with complex structure were likely to be underrepresented in the data (Sheaves and Johnston 2009). All sampling gears have associated biases (Bacheler et al. 2010, Catalano \& Allen 2010), so as with any gear type, cast net catches can only be interpreted in the context of gear-specific biases.

Samples were collected from a $4.3 \mathrm{~m}$ aluminium boat, fitted with an electric motor to reduce potential for disturbance, and followed the protocols set out by Sheaves et al. (2007). Samples were collected over the lower half of the tide, when small fish are forced out of the mangroves into the main channel of the estuary. Samples were collected along the banks of the estuaries because these areas contain the bulk of small fish throughout most of the lower part of the tidal cycle (Johnston and Sheaves 2008). Fish less than $5 \mathrm{~mm}$ body depth were excluded from analyses because these were below mesh selection size and so unlikely to be well represented in samples. Although Pacific seabream Acanthopagrus pacificus is the more common member of its genus in the region (Robertson and Duke 1990b; Sheaves 1996) very small individuals could not be separated from small individuals of Surf bream Acanthopagrus australis that also occurs in the region (Sheaves 1992), so data for the two species were pooled to the genus level to produce an Acanthopagrus spp. species complex. Fish were enumerated and CPUE calculated as numbers per 100 nets for each Estuary X Reach X Trip combination. Samples were returned to the laboratory for processing however because measuring the lengths of all individual fish was logistically prohibitive, individuals were allocated to $5 \mathrm{~mm}$ size classes by eye, with a ruler as a guide, and weighed by size class. Mean BPF was calculated for each Estuary X Reach X Trip combination. Maximum BPF was calculated as the mean biomass of individuals in the largest size class for each combination. Temporal patterns were investigated for the 20 species that occurred in at least $30 \%$ of Estuary X Reach X Trip combinations.

Three a priori groups were defined based on life-history strategies interpreted from published literature (Blaber and Blaber 1980; Robertson and Duke 1990a; Sheaves 1995; Tobin et al. 1997; Sheaves et al. 1999; Sheaves 2006; Johnston and Sheaves 2008; Froese and Pauly 2010; Sheaves and Johnston 2009); offshore spawners: species that spawn offshore and 
only occur in estuaries as juveniles, estuary species: species that have all life stages represented in estuaries, spawn in estuaries and are mainly confined to estuaries, and generalist species: usually larger species with a variety of life stages represented in estuaries but with adults and sometimes juveniles also occurring in other systems. The classification we used reflects the groupings of species driving the patterns observed in this study, but does do not align exactly with established functional typologies such as that of Elliott et al. (2007). Our "offshore spawner" group includes species that align with the "marine migrants" of Elliot et al. (2007) and species that fit the "estuary species" categorisation. A similar allocation problem exists with our "estuary species" and "generalist species" because different functional categories as defined by Elliott et al. (2007) are represented in each of those life-history groups.

Statistical Analysis Initial data modelling used univariate classification and regression trees (CARTs) to evaluate the effect of trip, estuary and reach on CPUE for each of the 20 common species (Table 2). CARTs recursively partition data into increasingly homogeneous subsets. Initial tree splits are typically more important (yield greater improvement in the fit of the model) than those that are closer to the bottom of the tree. With a numeric dependent variable (CPUE), split selection was based on minimising within-group sum-of-squared residual deviation of the resultant groups. The study focus was on temporal change but spatial factors were included to allow investigation of the spatial consistency of temporal change.

Selection of the final CART models was conducted using 10-fold cross validation, with the 1SE CART (the smallest CART with cross validation error within 1 SE of that of the CART with the minimum cross validation error) selected as the final CART model, a procedure that produces robust, biologically interpretable CARTs (Breiman et al. 1984; De'ath and Fabricius 2000). The importance of each variable was evaluated by its occurrence in the final 1-SE CART. Where CARTs showed substantial trip effects (trip accounted for all splits or comprised at least 2 splits and dominated the percent variance explained). Generalised Additive Models (GAMs), using cubic splines, were fitted to describe the patterns of changes in CPUE over time. GAMs were fitted to species data pooled across sites because the dominance of trip splits in the CARTs demonstrated that temporal patterns were consistent among sites for those species. The same approach was used to model BPF. CPUE data were $\log (\mathrm{x}+1)$ transformed and mean BPF data square root transformed before conducting analyses to maximize the homogeneity of distributions of residuals.

\section{Results}

Sampling of the 4 estuaries produced 70,664 fish from 102 species, 20 of which occurred in at least $30 \%$ of Estuary X Reach X Trip combinations (Table 2). Forty-eight percent of individuals were contributed by one species, the estuary resident Vachelli's glass perchlet Ambassis vachellii, $7 \%$ by another 32 estuary species, $41 \%$ by 49 offshore spawners and $4 \%$ by 20 generalist species.

Most species showed systematic variation in CPUE over space and time. Viable CART models for CPUE could be formed for 19 of the 20 common taxa (Table 2), with only 
Silver sillago Sillago sihama failing to show systematic variation over space or time. Three species, Buffon's river-garfish Zenarchopterus buffonis, the tretraodontid Marilyna pleurosticta and Scalloped perchlet Ambassis nalua showed only spatial effects. Overall patterns of temporal change in CPUE were characteristically different for the three a priori defined life-history groups.

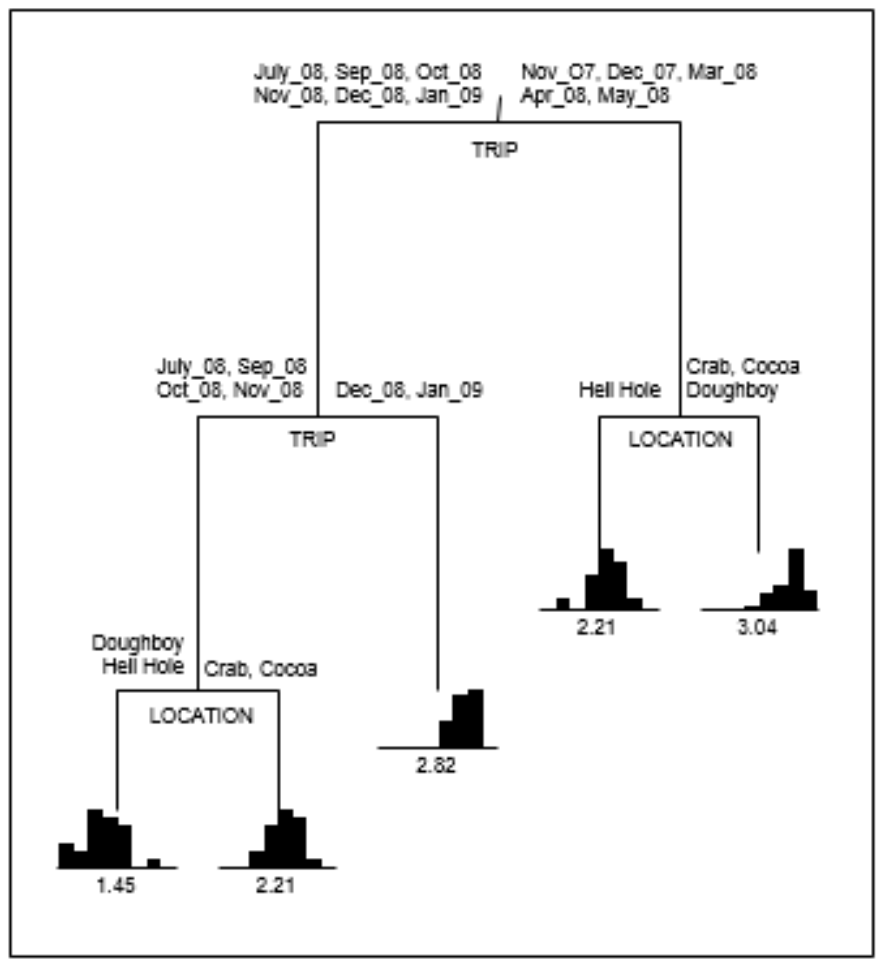

Fig. 2 Example of a fitted Classification and Regression Tree, as summarised in Table 2, for the effect of trip, estuary and reach on the CPUE of Leiognathus equulus. Upper case text below branches indicates the variable responsible for the split, text above branches indicates the levels of the variables partitioned to each branch of the split. The numbers below the branch indicate mean CPUE estimates for each terminal branch. The model explains $56 \%$ of the variance in CPUE (Table 2)

CART models explained a substantial amount of the total variation in CPUE for most offshore spawning species (Fig. 2, Table 2), with all except Whipfin silver-biddy Gerres filamentosus and Milkspotted puffer Chelonodon patoca showed both spatial and temporal variation; these showing only temporal patterns. Overall temporal change was substantially more influential than spatial variation and was consistent across estuaries and reaches. Temporal change accounted for at least $50 \%$ of the explained variability for all species except Indian anchovy Stolephorus indicus (27\%, Table 2). For all except two offshore spawners spatial splits were subordinate to temporal splits, meaning temporal patterns were similar among all estuaries, but within particular trips some location-specific differences could be detected. Although Broadhead anchovy Stolephorus brachycephalus did have an initial location split (CPUE at Cocoa and Hell Hole Creeks were lower than at Crab and Doughboy Creeks) the subsequent trip splits on both location branches were equivalent (i.e. there was no interaction), indicating the pattern of temporal change in S. brachycephalus CPUE was similar for all estuaries. The primary location split for $S$. indicus separated Hell Hole Creek (which had constantly low CPUEs) from the other estuaries, with the other estuaries subsequently differentiated by trip. Hence, despite some differences in absolute CPUE among some estuaries, temporal patterns were consistent among sites and explained more variance 
for most species than spatial patterns. Because of this, the GAMs used to examine temporal patterns in those species CPUE and BPF were fitted to species data pooled across sites. Offshore spawning species showed clear sinusoidal patterns in CPUE that were highest during the late pre-wet, wet and post-wet seasons, and lowest during dry and early pre-wet seasons; although the exact timing of maxima and minima varied among species (Fig. 3). The exception was $S$. indicus (not shown) that showed similar seasonal trends but displayed only weakly sinusoidal change.

CART modelling generally explained far less variation in CPUE of estuary species. Unlike offshore species, where both spatial and temporal factors were generally influential, systematic variation in CPUE of estuary species was usually attributable to only a single spatial or temporal effect (Table 2). Estuary species showed a variety of temporal patterns (Fig. 4). Two species, Ambassis vachellii and Castelnau's herring Herklotsichthys castelnaui demonstrated sinusoidal patterns in CPUE similar to those of offshore spawners.

Acanthopagrus spp. also showed a strong seasonal pattern but with lowest CPUEs during the post-wet and dry seasons. The other five estuary species either showed no temporal effects, in the cases of Marilyna pleurosticta, Zenarchopterus buffonis and Ambassis nalua (Table 2), or, in the case of Pacific blue-eye Pseudomugil signifer and Western Pacific gizzard shad Nematalosa come, had CPUE profiles that declined slightly throughout study (Fig. 4). Generalist species also showed varied patterns of temporal change in CPUE, although the systematic variation explained was generally small (Table 2). Javelin grunter Pomadasys kaakan showed seasonal change in CPUE similar to that of offshore spawners, while CPUE of Greenback mullet Liza subviridis was relatively stable throughout the study and that of Longfinned mullet Moolgarda perusii declined over time (Fig. 5).

Most offshore spawners showed temporal changes in mean BPF, with trip dominating explained variability for all species except Hamilton's thryssa Thryssa hamiltonii, where the influence of trip was relatively weak, and C. patoca that showed no clear temporal change (Table 2). Changes in mean BPF tended to be mirror images of the changes in CPUE (Fig. 3), with clear negative correlations between changes in mean BPF and changes in CPUE for Common ponyfish L. equulus, Decorated ponyfish Nuchequula gerreoides and G. filamentosus (Table 3). Taken together changes in CPUE and BPF of offshore species show a progression over time from larger numbers of small individuals in the late pre-wet and wet seasons to smaller numbers of large individuals during the dry and early pre-wet seasons (Fig. 3). Not only did small fish dominate (i.e. low mean BPFs) during periods when CPUEs were high but maximum BPFs tended to be low during these times indicating that large individuals were rare or absent (Fig. 6). 
Table 2

Summary of CART and GAM fits to CPUE and biomass per fish (BPF) data for fish occurring in $>30 \%$ of Estuary X Reach X Trip combinations. Data presented are: CART split order; the order of variables explaining splits from most to least variance explained. CART model \% var. expl; the percentage of total variance explained by the whole CART model, \% expl. var. due to trip; percentage of the total variance explained attributable to the factor trip, GAM coef. (non-linear p); GAM coefficient for the fitted model together with its estimated non-linear probability value, GAM $R^{2}$; estimated $\mathrm{R}^{2}$ of the fitted GAM model, Group; life-history group of each species ( off = offshore spawner, est = estuary species, gen = generalist species). Total sample sizes are given in brackets after species names

CPUE (per 100 nets)(log $(1+\mathrm{x})$ transformed)

\begin{tabular}{ccccc}
\hline & CART model & $\%$ expl. var. & GAM coef. & GAM \\
CART split order & \% var. expl. & due to trip & (non-linear $\mathrm{p}$ ) & $\mathrm{R}^{2}$
\end{tabular}

Mean BPF (square root transformed)

\begin{tabular}{|c|c|c|c|c|c|c|c|c|c|c|c|}
\hline & \multirow[b]{2}{*}{$\begin{array}{l}\text { ڤे } \\
\text { ثે }\end{array}$} & & \multirow[b]{2}{*}{$\begin{array}{c}\text { CART split } \\
\text { order }\end{array}$} & \multirow[b]{2}{*}{$\begin{array}{l}\text { CART model } \\
\text { \% var. exp. }\end{array}$} & \multirow[b]{2}{*}{$\begin{array}{l}\text { \% exp. var. } \\
\text { due to trip }\end{array}$} & \multirow{2}{*}{$\begin{array}{l}\text { GAM coef. } \\
\text { (non-linear } p \text { ) }\end{array}$} & \multirow[b]{2}{*}{$\begin{array}{l}\text { GAM } \\
\mathrm{R}^{2}\end{array}$} \\
\hline & & CART split order & $\begin{array}{l}\text { CART model } \\
\text { \% var. expl. }\end{array}$ & $\begin{array}{l}\% \text { expl. var. } \\
\text { due to trip }\end{array}$ & $\begin{array}{l}\text { GAM coef. } \\
\text { (non-linear } p \text { ) }\end{array}$ & $\begin{array}{l}\text { GAM } \\
\mathrm{R}^{2}\end{array}$ & & & & & \\
\hline Chelonodon patoca (117) & off & trip & 20 & 100 & $-0.047(0.020)$ & 0.44 & loc & 44 & & & \\
\hline Gerres filamentosus (421) & off & trip, trip & 44 & 100 & $-0.047(0.000)$ & 0.58 & trip, trip & 55 & 100 & $-0.039(0.240)$ & 0.72 \\
\hline Nuchequula gerreoides (1664) & off & trip, trip, loc & 47 & 79 & $-0.017(0.000)$ & 0.62 & trip, trip, rea, loc & 67 & 70 & $0.018(0.000)$ & 0.88 \\
\hline Leiognathus equulus (17972) & off & trip, trip, loc, loc & 56 & 70 & $-0.044(0.000)$ & 0.61 & $\begin{array}{l}\text { trip, trip, loc, } \\
\text { trip, loc, trip }\end{array}$ & 68 & 79 & $0.017(0.001)$ & 0.75 \\
\hline Secutor ruconius (1293) & off & trip, trip, trip, trip, loc & 60 & 90 & $-0.007(0.000)$ & 0.55 & trip, trip, loc & 73 & 90 & $-0.005(0.026)$ & 0.79 \\
\hline Stolephorus brachycephalus (1312) & off & loc, trip, trip, trip, trip, loc & 57 & 53 & $-0.019(0.000)$ & 0.30 & trip & 40 & 100 & $-0.017(0.018)$ & 0.71 \\
\hline Stolephorus indicus (346) & off & loc, trip, loc & 33 & 27 & $-0.020(0.183)$ & 0.16 & trip & 42 & 100 & $-0.008(0.015)$ & 0.75 \\
\hline Thryssa hamiltonii (3241) & off & trip, trip, loc, trip & 64 & 81 & $-0.063(0.000)$ & 0.53 & trip, loc & 30 & 42 & $-0.030(0.025)$ & 0.14 \\
\hline Acanthopagrus spp. (551) & est & trip, trip & 22 & 100 & $-0.019(0.000)$ & 0.45 & trip & 25 & 100 & $-0.159(0.130)$ & 0.66 \\
\hline Ambassis nalua (176) & est & rea & 27 & & & & & & & & \\
\hline Ambassis vachelli (34105) & est & trip, trip & 32 & 100 & $-0.064(0.000)$ & 0.50 & trip, trip, loc & 63 & 86 & $-0.001(0.051)$ & 0.61 \\
\hline
\end{tabular}




\begin{tabular}{|c|c|c|c|c|c|c|c|c|}
\hline Herklotsichthys castelnaui (1329) & est & loc, trip, trip & 28 & 54 & $-0.022(0.018)$ & 0.26 & no model & \\
\hline Marilyna pleurosticta (237) & est & loc & 21 & & & & loc & 38 \\
\hline Nematalosa come (499) & est & trip & 25 & 100 & $-0.067(0.077)$ & 0.40 & no model & \\
\hline Pseudomugil signifer (1921) & est & trip, trip, trip & 28 & 100 & $-0.060(0.052)$ & 0.31 & no model & \\
\hline Zenarchopterus buffonis (592) & est & loc & 26 & & & & & \\
\hline Liza subviridis (1874) & gen & trip & 18 & 100 & $-0.011(0.026)$ & 0.24 & no model & \\
\hline Moolgarda perusii (457) & gen & trip & 12 & 100 & $-0.054(0.011)$ & 0.45 & no model & \\
\hline Pomadasys kaakan (188) & gen & trip, trip & 38 & 100 & $-0.037(0.000)$ & 0.55 & no model & \\
\hline Sillago sihama (140) & gen & no model & & & & & & \\
\hline
\end{tabular}


Relationships between CPUE and BPF were quite different for estuary and generalist species (Figs 4, 5). Acanthopagrus spp. and A. vachellii were the only estuary fish to show temporal change in BPF (Table 2). As with offshore species, correlations between BPF and CPUE of Acanthopagrus spp. and A. vachellii tended to be negative (Table 3). However, in contrast to offshore species, maximum BPF tended to be stable over time for A. vachellii (Fig. 7), indicating the continued presence of larger individuals even at times when small fish dominated catches. Acanthopagrus spp. did show seasonal changes in maximum BPF (Fig. 7) but the importance of this is difficult to judge because Acanthopagrus spp. reach large sizes in estuaries (Sheaves et al. 1999), and larger Acanthopagrus spp. are likely to be poorly represented in cast net samples (Sheaves et al. 2007). Other estuary species lacked systematic change in BPF over time as did all generalist species (Table 2).

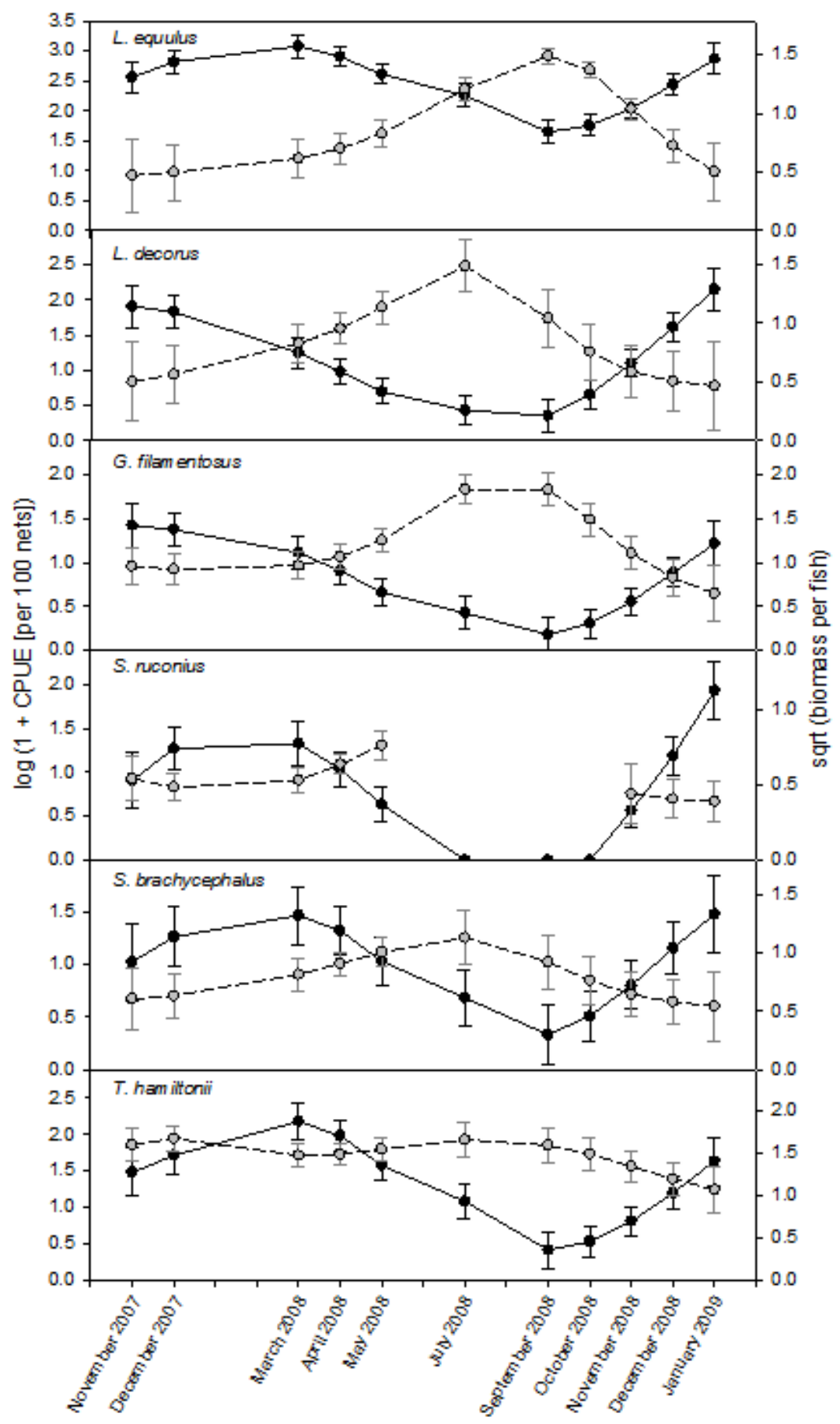

Fig. 3 Fitted GAM models for CPUE (black symbols) and BPF (grey symbols) for six offshore spawning species. Error bars are $95 \%$ confidence intervals 
Table 3

Correlations between CPUE \& BPF for species where CART analyses showed temporal effects of both variables

\begin{tabular}{lcc}
\cline { 2 - 3 } & \multicolumn{2}{c}{ CPUE v BPF } \\
\cline { 2 - 3 } & \multicolumn{1}{c}{$\mathrm{r}$} & $\mathrm{p}$ \\
\hline L. equulus & -0.89442 & 0.0002 \\
\hline N. gerreoides & -0.8327 & 0.001 \\
\hline G. filamentosus & -0.83458 & 0.001 \\
\hline S. ruconius & -0.53241 & 0.174 \\
\hline S. brachycephalus & -0.39341 & 0.231 \\
\hline S. indicus & -0.03061 & 0.933 \\
\hline T. hamiltonii & -0.0606 & 0.860 \\
\hline A. vachelli & -0.45884 & 0.156 \\
\hline Acanthopagrus spp. & -0.46455 & 0.150
\end{tabular}


Table 4

Comparison of patterns of variation in CPUE and BPF for Offshore and Estuary species. Patterns for generalists were inconsistent (see Table 2)

Offshore spawners $\quad$ Estuary species

\begin{tabular}{|c|c|c|c|}
\hline \multirow{4}{*}{ CPUE } & $\begin{array}{l}\text { total variation } \\
\text { explained }\end{array}$ & usually $>40 \%$ & $<40 \%$ \\
\hline & $\begin{array}{l}\text { explanatory } \\
\text { variables }\end{array}$ & $\begin{array}{l}\text { spatial and temporal variables } \\
\text { important but temporal greater } \\
\text { explanatory power }\end{array}$ & $\begin{array}{l}\text { usually a single spatial or } \\
\text { temporal factor }\end{array}$ \\
\hline & $\begin{array}{l}\text { pattern of temporal } \\
\text { change }\end{array}$ & $\begin{array}{l}\text { all sinusoidal, highest during the } \\
\text { warmer, wetter seasons }\end{array}$ & $\begin{array}{l}\text { various, over half showing no } \\
\text { seasonal pattern }\end{array}$ \\
\hline & $\begin{array}{l}\text { timing of maxima } \\
\text { \& minima }\end{array}$ & species specific & species specific \\
\hline \multirow{2}{*}{ BPF } & $\begin{array}{l}\text { substantial } \\
\text { temporal changes }\end{array}$ & all species & 2 of 9 species \\
\hline & $\begin{array}{l}\text { explanatory } \\
\text { variables }\end{array}$ & dominantly trip & trip and spatial \\
\hline joint temporal & $\begin{array}{l}\text { coincidence of } \\
\text { patterns }\end{array}$ & mirror images & inconsistent \\
\hline \& BPF & $\begin{array}{l}\text { presence of large } \\
\text { individuals }\end{array}$ & $\begin{array}{l}\text { rare or absent when CPUE was } \\
\text { hig }\end{array}$ & throughout the year \\
\hline
\end{tabular}




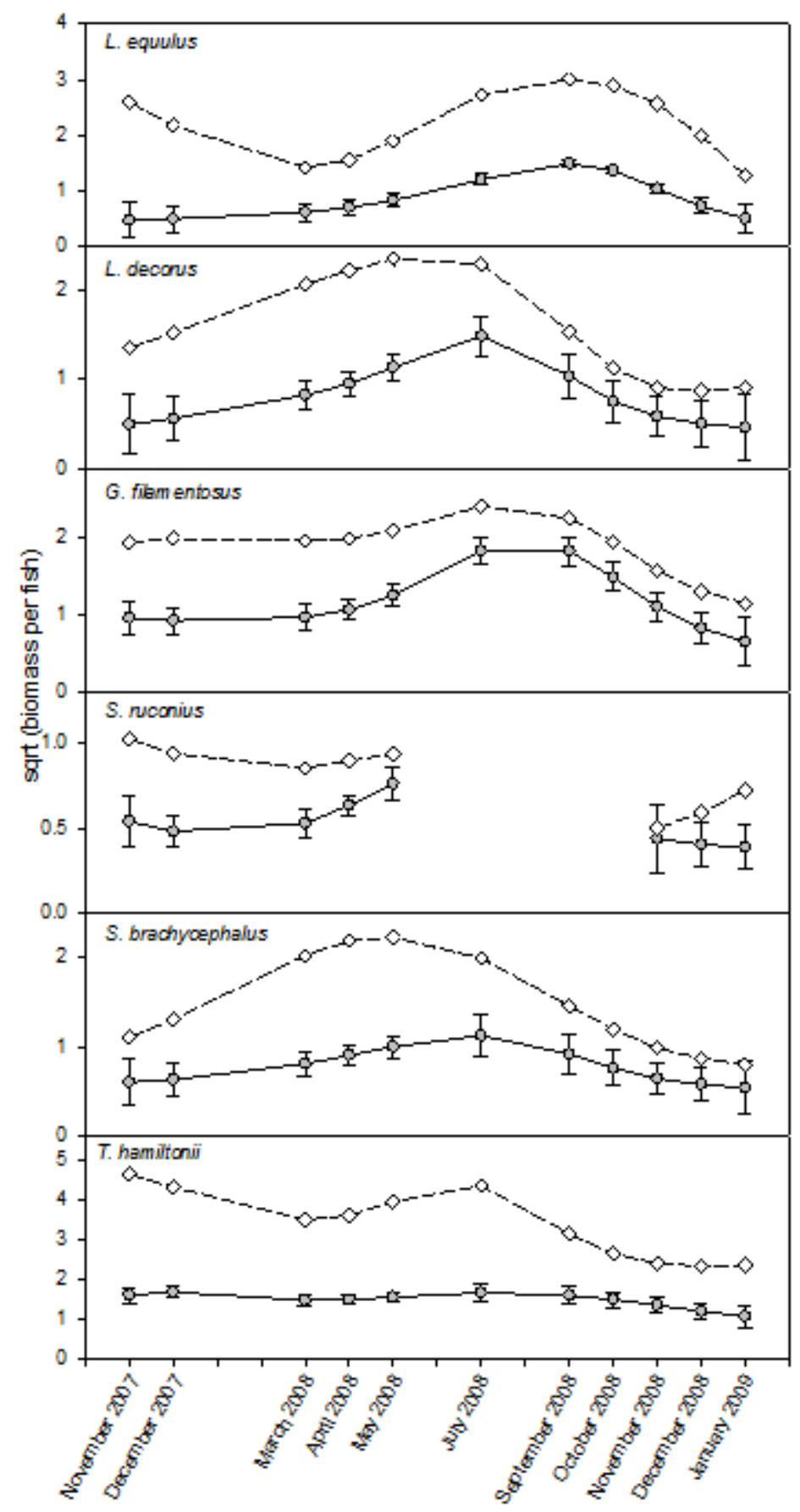

Fig. 6 Relationship between mean (grey symbols) and maximum (open symbols) BPF for offshore spawning species 


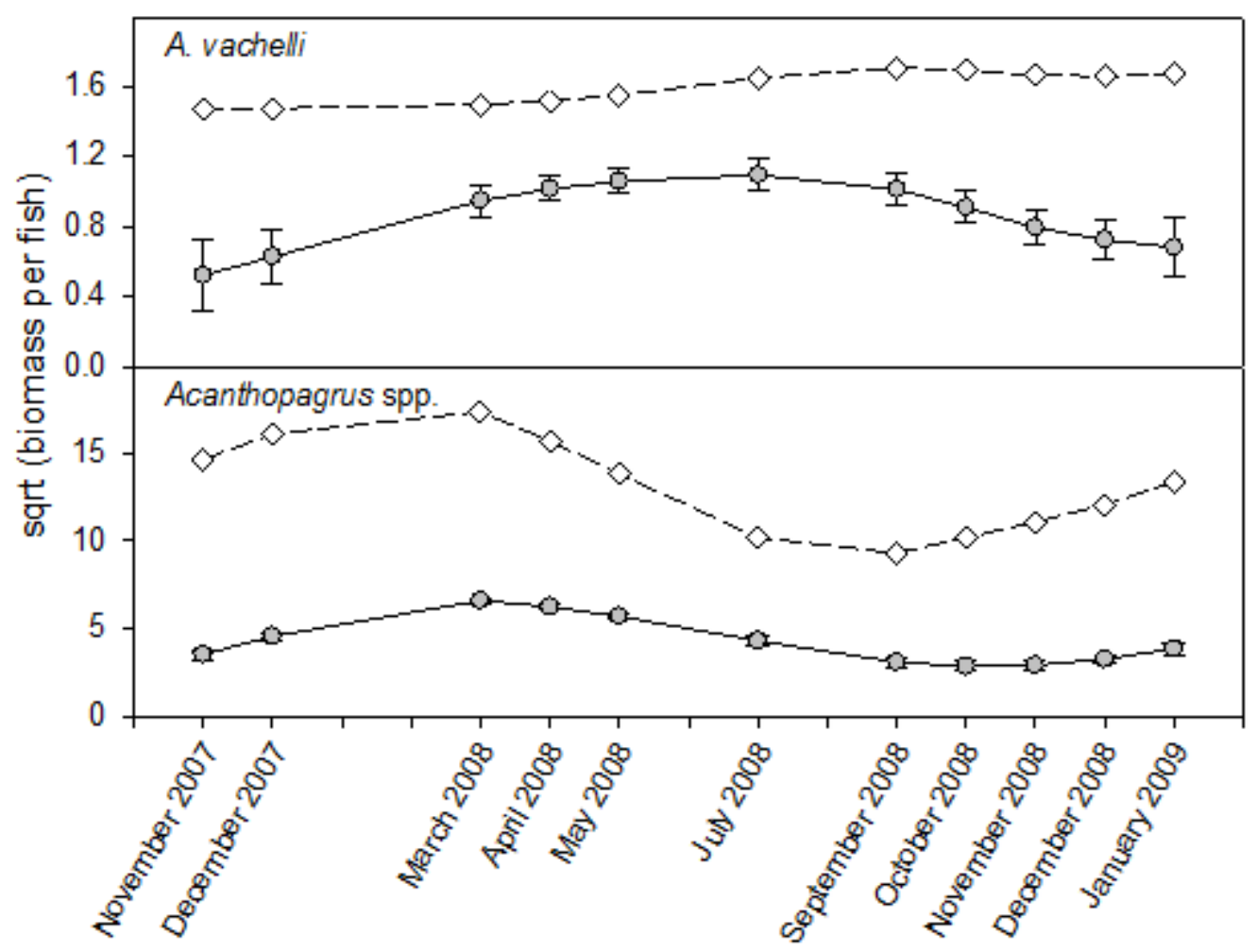

Fig. 7 Relationship between mean (grey) and maximum (open) BPF for the two estuary species that formed viable CART models for BPF

\section{Discussion}

Temporal patterns in assemblage structure The three a priori life-history groups manifested characteristically different patterns of temporal change that have substantial implications for the structure, functioning, and management of tropical estuarine fish assemblages. Patterns of CPUE, BPF, and the relationships between CPUE and BPF were quite different for offshore spawned species and those of estuary resident or generalist species (Table 4). The simple spatial and temporal factors investigated were more important for offshore spawners than estuary species, both in terms of the amount of the variation explained for individual species and the proportion of species showing systematic spatio-temporal change. Temporal change had substantial explanatory power for offshore spawners, with all species showing systematic changes in both CPUE and BPF that strongly suggested seasonal change driven by the spawning-recruitment-growth-migration cycle of estuarine nursery use, in agreement with the findings of Robertson and Duke (1990a). Over half of the estuary spawners showed no seasonal pattern in CPUE and only two showed temporal change in BPF. In contrast to offshore species, where large individuals were rare when CPUE was high, large individuals were present throughout the year for the estuary species that showed temporal change in both CPUE and BPF, indicating the continued presence of larger individuals even at times when small fish dominated catches. Although three generalist species showed weak temporal change in CPUE none displayed temporal variation in BPF.

Contrasting temporal changes in CPUE and BPF reflect the way the different lifehistory groups use estuaries. The use of estuaries as short term nursery grounds for many offshore spawners is manifest in the seasonal shifts in the balance between size and abundance. In contrast, the persistent presence of estuary spawners throughout the year is seen in a general lack of strong pattern of temporal change, particularly in individual biomass. Even the hyper-abundant $A$. vachellii that did show seasonal changes in both CPUE 
and BPF, showed little change in maximum size over the year.

Generalist species demonstrated only weak temporal changes in CPUE, usually without any distinct pattern, and no systematic changes in BPF. This probably had two main causes. Firstly, generalists are distributed across estuaries and near coastal waters in the region and probably interchange freely among habitat units in the coastal ecosystem mosaic (CEM) (Sheaves 2009). As a result they display relatively high levels of variability in CPUE and individual biomass making any patterns difficult to detect. Secondly, unlike offshore spawners and the majority of estuary species, where estuarine populations mainly comprise individuals less than one year old, many year classes of generalists are present at any one time leading to greater stability in overall abundances and individual biomass. The presence of large individuals is also likely to lead to sampling biases because they are less vulnerable to cast nets than small fish (Sheaves et al. 2007) increasing the difficulty in detecting patterns of change if they exist. 


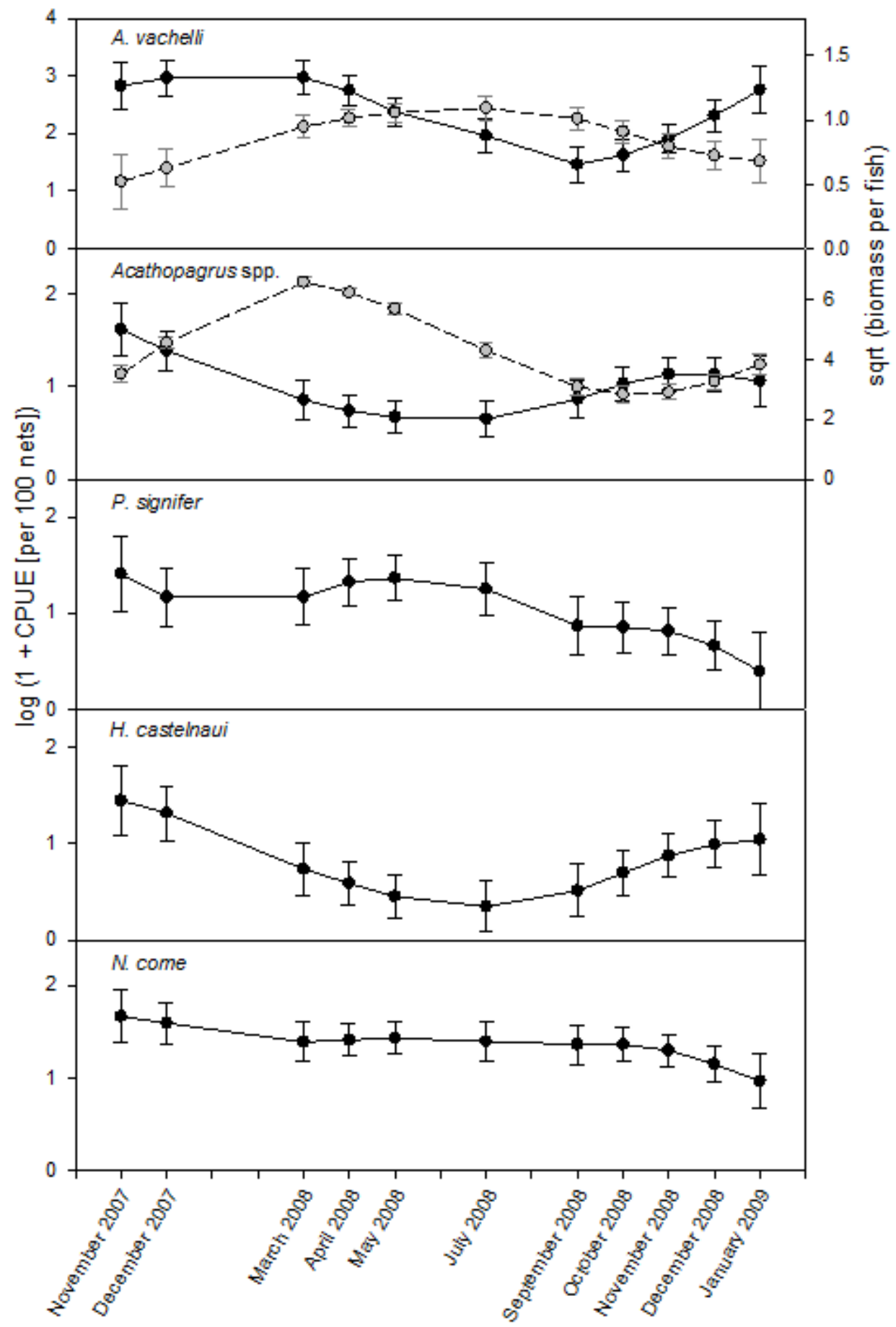

Fig. 4 Fitted GAM models for CPUE (black) and BPF (grey) for five estuary species with substantial temporal effects in their fitted CART models. Only Ambassis vachellii and Acanthopagrus spp. formed viable CART models for BPF. Error bars are $95 \%$ confidence intervals 
Figure 5

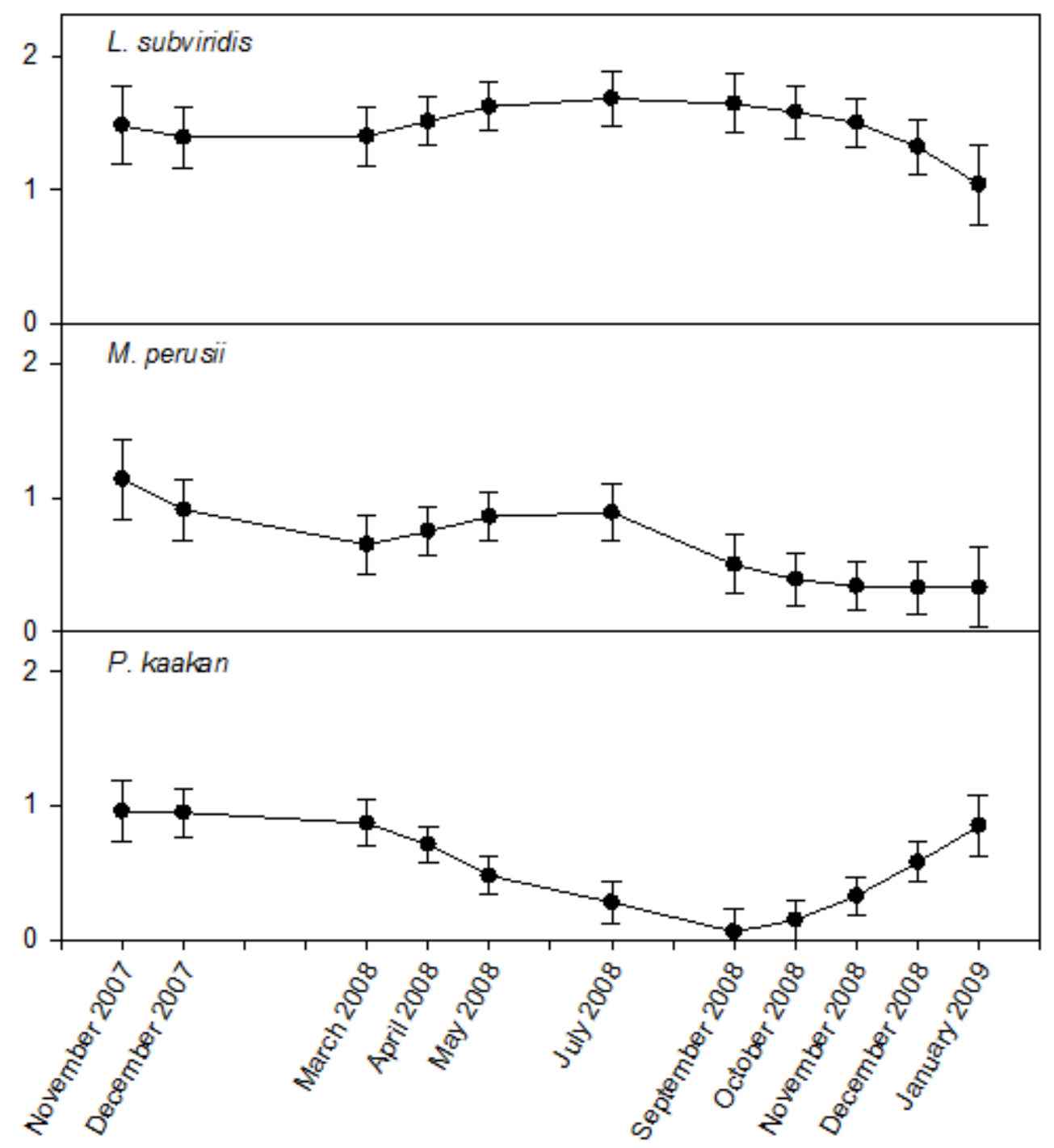

Fig. 5 Fitted GAM models for CPUE for three generalist species with substantial temporal effects in their fitted CART models. Viable CART models for BPF were not produced for any generalist species. Error bars are $95 \%$ confidence intervals

The results of the present study largely agree with those of Robertson and Duke's (1990a) study of the recruitment and residence time of fish in Alligator Creek, an estuary within the area of the current study. This suggests that the rapid data gathering approach used in the present study was a useful trade-off for investigating coarse-grained pattern in a large data set. The approach utilised joint patterns of change in catch per unit effort (CPUE) and mean and maximum biomass per fish (BPF) as proxies for changes in size structure. This enabled us to process much larger sample sizes than Robertson and Duke (1990a) (9 species over 1000 individuals for the present study compared to 2 species over 1000 individuals for Robertson and Duke (1990a), and over 10 times as many A. vachellii (A. gymnocehpalus in Robertson and Duke (1990a)) and L. equulus, the two most abundant species in both studies), and allowed us to investigate temporal change across four estuaries. Although Robertson and Dukes' (1990a) length-frequency approach was undoubtedly more precise, the large investment in time needed to collect length-frequency data forced them to make a different trade-off and only process a subsample of their data (N. Duke pers. com.).

Drivers of temporal change Seasonal changes in the abundance and size structure of the offshore spawner component of northeastern Australia's estuary fish fauna seem likely to 
be a major driver of fish assemblage changes in tropical estuaries. Offshore spawners comprised a substantial component of catch in terms of both numbers of species and total CPUE in this and previous (e.g. Robertson and Duke 1990b; Sheaves and Johnston 2009) studies of tropical estuaries, with patterns of change consistent among species. Thus their large seasonal changes in CPUE lead to periods when offshore spawners dominate catches and periods when they are minor components. Additionally, local recruitment of offshore spawners to particular estuaries is likely to be regulated by larval supply which may show strong spatial patterning (Fontes et al. 2009). Consequently, the dominant joint temporal progression in CPUE and BPF for offshore spawners signifies a strong contribution from their recruitment-migration/mortality cycle to overall spatial differences in fish assemblage compositions over time (Sheaves 2006; Sheaves and Johnston 2010). However, the yearround presence of a diverse and abundant estuary spawner component that display different temporal patterns to offshore spawners, and of generalist species demonstrating little temporal pattern, modifies the seasonal pattern imposed by offshore spawners. The interaction of these 3 life-history groups provides the opportunity for complex assemblage patterns that are likely to be sensitive to location-specific differences in the mix of species from each group, and provides at least part of the explanation for the site specific fish assemblage structures that are characteristic of tropical estuarine fish fauna (Sheaves and Johnston 2009).

The three life-history groups relate to estuaries at very different spatial, temporal, and conceptual scales. Offshore spawners found in estuaries are the juvenile components of spatially extensive populations and are just one phase in the species' life-histories. They equate to the "mesopopulations" of Forrester et al. (2002) and are temporally explicit components of spatially extensive populations (Kritzer and Sale 2004). In contrast, individual estuary spawner populations are essentially closed (Kritzer and Sale 2004). All life-history phases occur within each estuary and the size of local populations are not significantly influenced by recruits from other estuaries meaning their dynamics conform to the membervagrant pattern (Sinclair 1989). For generalist species, estuaries only represent one "patch" in the larger CEM (Sheaves 2009). Consequently, different key processes are likely to affect the abundance of each life-history group (Hixon et al. 2002), while processes that are important for all life-history groups are likely to impact each group differently to produce different ecological outcomes. For instance, the abundance of new recruits of estuary residents will be related to the past size of local adult populations, while the strength of offshore spawner recruitment is likely to be decoupled from previous abundances in the particular estuary. This means that population dynamics of the two groups are likely to be controlled by very different forces, with differences in the relative importance of larval supply versus post recruitment process in regulating populations (Armsworth 2002). Processes regulating populations may also act in spatially separate ecosystems for different groups (Ritter and Preisler 2006). Moreover, the three life-history groups have different schedules of occupancy of estuarine habitats, and of movement between estuaries and other components of the CEM. As a result the different life-history groups connect the various components of the CEM in different ways, and over different scales, adding complexity to overall assemblage spatiotemporal dynamics.

Interacting patterns of change in abundance and size over the year also have implications for the local regulation of populations of the fish assemblage, their prey and their predators. The offshore spawners studied are small benthic invertebrate feeders or planktivores. The large fluctuations in abundance they undergo mean that their prey populations would be under substantial pressure during periods of high fish abundance 
(Osman and Whitlatch 2004; Horppila et al. 2009) providing the potential for bottlenecks that could regulate both the abundance of prey and the growth and survival of the fish themselves. At the same time, these periods of high abundance would provide large numbers of prey fish that could support an abundance of predators (e.g. Juanes and Conover 1995; Baker and Sheaves, 2009a), but predator abundances would be limited by low numbers of prey fish when few offshore spawners were present. This could be offset by predators switching to feed on estuary residents, alternate prey, or moving to other habitats, but any of these responses again adds considerable complexity to overall community dynamics (Baker and Sheaves 2009b).

Implications for management Management, monitoring, and assessment are all complicated by an estuary fish fauna comprising three distinct functional components. The major factors regulating the abundances of each group are likely to be quite different and population regulation will occur in a different way and often at a different place for each lifehistory group. This means that managing impacts on one component will not necessarily ensure the health of the other components, just as failure to detect change in one component will not necessarily ensure substantial change is not occurring in the other components. Consequently, monitoring and assessment needs to consider the three components separately and evaluate observed changes differently. For instance, changes in the local abundance of estuary residents are likely to be responses to events within the particular estuary, while changes in the abundance of offshore spawners in a particular estuary may be driven by a great range of processes or impacts acting on life stages well beyond the estuary itself.

\section{Acknowledgements}

We thank the many volunteers who made the field work for this project possible. The work was supported by a Marine and Tropical Sciences Research Facility (MTSRF) research grant. Research was conducted under James Cook University Ethics Approval A1210.

\section{References}

Aiken, S., E. Buhan, K.O. Winemiller, H. Yilmaz. 2005. Fish assemblage structure of Koycegiz Lagoon-Estuary, Turkey: Spatial and temporal distribution patterns in relation to environmental variation. Estuarine, Coastal and Shelf Science 64: 671-684.

Armsworth, P.R. 2002. Recruitment limitation, population regulation, and larval connectivity in reef fish metapopulations. Ecology 83: 1092-1104.

Bacheler, N.M., J.E. Hightower, S.M. Burdick, L.M. Paramorec, J.A. Buckela, K.H. Pollock 2010. Using generalized linear models to estimate selectivity from short-term recoveries of tagged red drum Sciaenops ocellatus: Effects of gear, fate, and regulation period. Fisheries Research 102:266-275. 
Baker, R., T.J. Minello. 2011. Trade-offs between gear selectivity and logistics when sampling nekton from shallow open water habitats: A gear comparison study. Gulf and Caribbean Research 23: 37-48.

Baker, R., M. Sheaves. 2009a. Refugees or ravenous predators: detecting predation on new recruits to tropical estuarine nurseries. Wetlands Ecology and Management 17: 317 330.

Baker, R., M. Sheaves. 2009b. Overlooked small and juvenile piscivores dominate shallowwater estuarine "refuges" in tropical Australia. Estuarine Coastal Shelf Science 85: 618-626.

Barletta, M., A. Barletta-Bergan, U. Saint-Paul, G. Hubold. 2005. The role of salinity in structuring the fish assemblages in a tropical estuary. Journal of Fish Biology 66: 4572.

Blaber, S.J.M. 1980. Fish of the Trinity Inlet system of north Queensland with notes on the eology of fish faunas of tropical Indo-Pacific estuaries. Australian Journal of Marine and Freshwater Research 31: 137-146.

Blaber, S.J.M. 2002. 'Fish in hot water': the challenges facing fish and fisheries reseearch in tropical estuaries. Journal of Fish Biology 61A: 1-20

Blaber, S.J.M., T.G. Blaber. 1980. Factors affecting the distribution of juvenile estuarine and inshore fish. Journal of Fish Biology 17: 143-162.

BOM. 2009. Australian Bureau of Meterology. Australian Department of Environment, Water, Heritage and the Arts, Canberra. http//www.bom.gov.au

Breiman, L., J. Friedman, R. Olshen, C. Stone. 1984. Classification and regression trees. Wadsworth Internation Group, Belmont, 358pp.

Catalano, M.J., M.S. Allen. 2010. A size- and age-structured model to estimate fish recruitment. Fisheries Research 105:38-45.

growth, mortality, and gear selectivity

De'ath, G., K.E. Fabricius. 2000. Classification and regression trees: a powerful yet simple technique for ecological data analysis. Ecology 81: 3178-3192.

Deegan, L.A., J.E. Hughes, R.A. Rountree. 2000. Salt marsh ecosystem support of marine transient species. In Concepts and Controversies in Tidal Marsh Ecology, eds. M.P. Weinstein and D.A. Kreeger, 333-365. Dordrecht: Kluwer Academic Publishers.

Elliott, M., A.K. Whitfield, I.C. Potter, S.J.M. Blaber, D.P. Cyrus, F.G. Nordlie, T.D. Harrison. 2007. The guild approach to categorizing estuarine fish assemblages: a global review. Fish and Fisheries 8: 241-268.

Fontes, J., J.E. Caselle, P. Afonso, R.S. Santos. 2009. Multi-scale recruitment patterns and effects on local population size of a temperate reef fish. Journal of Fish Biology 75: 1271-1286.

Forrester, G.E., R.R. Vance, M.A. Steele. 2002. Simulating Large-Scale Population Dynamics Using Small-Scale Data. In Coral Reef Fishes, Dynamics and Diversity in a Complex Ecosystem, eds. Peter F. Sale, 275-302. London: Academic Press 
Franco A., M. Elliott, P. Franzoi, P. Torricelli. 2008. Life strategies of fishes in European estuaries: the functional guild approach. Marine Ecology Progress Series 354: 219 228.

Froese, R., D. Pauly. 2010. FishBase: World Wide Web electronic publication. www.fishbase.org.

Garcia, A.M., J.P. Vieira, K.O. Winemiller, L.E. Moraes, E.T. Paes. 2012. Factoring scales of spatial and temporal variation in fish abundance in a subtropical estuary. Marine Ecology Progress Series 461: 121-135.

Hixon, M.A., S.W. Pacala, S.A. Sandin. 2002. Population regulation: Historical context and contemporary challenges of open vs. closed systems. Ecology 83: 1490-1508.

Horppila, J., P. Eloranta, A. Liljendahl-Nurminen, J. Niemisto, Z. Pekcan-Hekim. 2009. Refuge availability and sequence of predators determine the seasonal succession of crustacean zooplankton in a clay-turbid lake. Aquatic Ecology 43: 91-103.

Johnston, R., M. Sheaves. 2008. Cross-channel distribution of small fish in tropical and subtropical coastal wetlands depends on their trophic and taxonomic identities and on wetland depth. Marine Ecology Progress Series 357: 255-270.

Juanes, F., D.O. Conover. 1995. Size-structured piscivory: Advection and the linkage between predator and prey recruitment in young-of-the-year bluefish. Marine Ecology Progress Series 128: 287-304.

Kritzer, J.P., P.F. Sale. 2004. Metapopulation ecology in the sea: from Levins' model to marine ecology and fisheries science. Fish and Fisheries 5: 131-140.

Ley, J.A. 2005. Linking fish assemblages and attributes of mangrove estuaries in tropical Australia: criteria for regional marine reserves. Marine Ecology Progress Series 305 : 41-57.

Osman, R.W., R.B. Whitlatch. 2004. The control of the development of a marine benthic community by predation on recruits. Journal of Experimental Marine Biology and Ecology 311: 117-145.

Ritter, A.F., R.K. Preisler. 2006. Spatial variation in structure of an intertidal fish assemblage reflects daily settlement patterns. Marine Ecology Progress Series 317: 211-223.

Robertson, A.I., N.C. Duke. 1990a. Recruitment, growth and residence time of fishes in a tropical Australian mangrove system. Estuarine Coastal and Shelf Science 31: 723743.

Robertson, A.I., N.C. Duke. 1990b. Mangrove fish-communities in tropical Queensland, Australia: Spatial and temporal patterns in densities, biomass and community structure. Marine Biology 104: 369-379.

Sheaves, M.J. 1992. Patterns of distribution and abundance of fishes in different habitats of a mangrove-lined tropical estuary, as determined by fish trapping. Australian Journal of Marine and Freshwater Research 43: 1461-1479.

Sheaves, M. 1995. Large lutjanid and serranid fishes in tropical estuaries: Are they adults or juveniles? Marine Ecology Progress Series 129: 31-40. 
Sheaves, M.J. 1996. Habitat-specific distributions of some fishes in a tropical estuary. Marine and Freshwater Research 47: 827-830.

Sheaves, M.J. 2006. Scale dependent variation in composition of fish fauna among tropical estuarine sandy embayments. Marine Ecology Progress Series 310: 173-184.

Sheaves, M. 2009. The Consequences of Ecological Connectivity: the Example of the Coastal Ecosystem Mosaic. Marine Ecology Progress Series 391: 107-115.

Sheaves, M., R. Johnston, K. Abrantes. 2007. Fish fauna of dry sub-tropical estuarine floodplain wetlands. Marine and Freshwater Research 58: 931-943.

Sheaves, M., R. Johnston. 2008. Influence of marine and freshwater connectivity on the dynamics of subtropical estuarine wetland fish metapopulations. Marine Ecology Progress Series 357:225-243.

Sheaves, M., R. Johnston. 2009. Ecological drivers of spatial variability among fish fauna of 21 tropical Australian estuaries. Marine Ecology Progress Series 385: 245-260.

Sheaves, M., R. Johnston. 2010. Implications of Spatial Variability of Fish Assemblages for Monitoring of Australia's Tropical Estuaries. Aquatic Conservation Marine and Freshwater Systems 20: 348356.

Sheaves, M., R. Johnston, R. Connolly. 2010. Temporal dynamics of fish assemblages of natural and artificial tropical estuaries. Marine Ecology Progress Series 410: 143-157.

Sheaves, M.J., B.W. Molony, A.J. Tobin. 1999. Spawning migrations and local movements of a tropical sparid fish. Marine Biology 133: 123-128.

Sinclair, M., T. Iles. 1989. Population regulation and speciation in the oceans. ICES Journal of Marine Science 45: 165-175.

Tobin, A., M. Sheaves, B. Molony. 1997. Evidence of sex change in the tropical sparid, Acanthopagrus berda. Journal of Fish Biology 50: 22-33. 